\title{
Human Wharton's Jelly Mesenchymal Stem Cells Maintain the Expression of Key Immunomodulatory Molecules When Subjected to Osteogenic, Adipogenic and Chondrogenic Differentiation In Vitro: New Perspectives for Cellular Therapy
}

\author{
Giampiero La Rocca $^{\#, 1,2}$, Melania Lo Iacono ${ }^{\#, 2}$, Tiziana Corsello ${ }^{1,2}$, Simona Corrao ${ }^{2}$, \\ Felicia Farina ${ }^{1}$ and Rita Anzalone*,
}

${ }^{1}$ Sezione di Anatomia Umana, Dipartimento di Biomedicina Sperimentale e Neuroscienze Cliniche (BIONEC), Univer-
sità degli Studi di Palermo, Italy; ${ }^{2}$ Istituto Euro-Mediterraneo di Scienza e Tecnologia (IEMEST), Palermo, Italy

\begin{abstract}
Rheumatoid arthritis and osteoarthritis are the main diseases that imply an inflammatory process at the joints involving the articular cartilage. Recently, mesenchymal stem cells (MSCs) derived from perinatal tissues were considered good candidates for cellular therapy of musculoskeletal and orthopaedic diseases, since they can differentiate into multiple cell types and are an easily accessible cellular source. Therefore, several protocols exist on the differentiation of mesenchymal stem cells of different origins into osteoblasts and chondrocytes. Another key feature of MSCs is their capacity to modulate the immune system responses in vitro and in vivo. This may have critical outcomes in diseases of the musculoskeletal system where an inflammatory or autoimmune process is at the basis of the main disease.

In the present paper, after isolation of MSCs from Wharton's Jelly (WJ-MSCs), we performed the three standard differentiation protocols. The acquisition of the differentiated phenotype was demonstrated by the specific histological stains. As the main objective of this work, we determined the expression of immunomodulatory molecules (by immunohistochemistry and qualitative RT-PCR), both in undifferentiated cells and after differentiation. We demonstrated for the first time that immune-related molecules (as B7-H3/CD276 and HLA-E) which have been characterized in undifferentiated MSCs, are also expressed by the differentiated progeny. This strongly suggests that also after the acquisition of a mature phenotype, WJ-MSCs-derived cells may maintain their immune privilege. This evidence, which deserves much work to be confirmed in vivo and in other MSCs populations, may provide a formal proof of the good results globally achieved with WJMSCs as cellular therapy vehicle.
\end{abstract}

Keywords: Regenerative medicine, mesenchymal stem cells, umbilical cord, Wharton's jelly, immune modulation, tissue repair, osteogenic differentiation, adipogenic differentiation, chondrogenic differentiation.

\section{INTRODUCTION}

As reported by World Health Organization (WHO), the main causes of disability in the world are rheumatic, orthopaedic and musculoskeletal diseases. Rheumatoid arthritis (RA) and osteoarthritis (OA) are two diseases responsible of inflammation of the joints [1].

In OA, inflammatory process represents the result of pathogenetic condition, while in RA it is the main cause [2].

Both diseases, as well as isolated chondral and osteochondral disorders, involve injuries to articular cartilage, a type of hyaline cartilage composed by small chondro

*Address correspondence to this author at the Sezione di Anatomia Umana, Dipartimento di Biomedicina Sperimentale e Neuroscienze Cliniche (BIONEC), Università degli Studi di Palermo, Via del Vespro 12990127 Palermo, Italy; Tel: 00390916553510; Fax: 00390916553580;

E-mail: rita.anzalone@unipa.it; ranzalone@hotmail.com

\# These authors equal contributed to this work. cytes and a granular matrix, where is possible to distinguish three different classes of macromolecules: fibrillar and non-fibrillar collagens, collagenous proteins and proteogly [3-4].

It has been demonstrated that an imbalance between catabolic and anabolic functions of the chondrocytes may determine a cartilage injury. In addition, since chondrocytes are fed by diffusion via the synovial fluid, both growth and repair of cartilage are very slow [5].

For these reasons, some research groups investigated alternative methods to promote cartilage formation (such as osteotomy, joint distraction, implants of growth factors or artificial matrices), or to replace the chondrocytes by cell transplantation [6-7].

Chondrogenesis and Chondrocyte Differentiation Process

Chondrogenesis is a dynamic cellular process that involves the formation of hyaline, fibrous and elastic cartilage both during embryogenesis and in adult life. The process of 
chondrogenesis begins with aggregation and condensation of mesenchymal cells with the involvement of bone morphogenetic proteins (BMPs) [8]. In this phase, the condensed mesenchyme expresses some extracellular matrix and cell adhesion molecules such as IIa splice form of type II collagen [Col2a1(IIa)] [9, 10], N-cadherin (Ncad) [11], neural cell adhesion molecule (Ncam1) [12], tenascin C (Tnc) [13], and SRY-box 9 (Sox9), transcription factor involved in the early stages of chondrogenesis [14].

Subsequently, the chondrogenesis process is characterized by early chondrocyte differentiation and development of the cartilage template and by chondrocyte maturation and hypertrophy. If osteogenesis has to follow, during maturation steps, the chondrocytes differentiate, mineralize and undergo apoptosis. When the chondrocytes die, cartilage matrix deposits constitute the basis for mineral deposition and bone formation. In this phase, degraded cartilage will be invaded by blood vessels establishing the bone marrow cavity [15].

\section{Articular Cartilage Tissue Engineering and Factors In- volved in Chondrogenic Differentiation}

Hyaline cartilage of the limb and trunk skeleton derives from differentiation of mesenchymal stem cells that condense into clusters of cartilage cells (chondrocytes). Physiologically, this cartilage type is susceptible to both normal and pathologic stress [15]. In particular, articular cartilage may undergo degenerative processes involving focal and progressive cartilage loss. The main risk factors are linked to genetic background, obesity, advanced age, ethinicity, osteochondral and chondral lesions and OA.

In the last years, tissue engineering was considered the main approach for repair of articular cartilage lesions. Autologous, heterotypic and allogenic chondrocytes were expanded in culture [16].

The presence in culture media of specific growth factors such as members of TGF- $\beta$ (transforming growth factor $-\beta$ ) superfamily, insulin like growth factor (IGF), hepatocyte growth factor (HGF) and BMPs can influence the chondrocyte phenotype [17]. BMPs belong to the TGF- $\beta$ superfamily and can promote ectopic cartilage and bone formation through a direct regulation of the expression of chondrocyte genes [18].

Bone morphogenetic protein-2 (BMP-2) together with TGF- $\beta$, can influence the synthesis of type II collagen, the main marker to evaluate acquisition of chondrocyte phenotype. Some authors demonstrated that in costal embryonic mouse chondrocytes, the presence in culture of BMP-2 induced the expression of type IIB and $\alpha-10$ integrin, while TGF- $\beta 1$ potentiated the expression of type IIA and $\alpha 11$ integrin $[19,20]$.

Another work highlighted that the addition of BMP-2 in monolayer cultures of nasal chondrocytes, could reactivate the chondrogenic expression programme, in particular inducing the expression of type II collagen gene by enhancing DNA-binding of the SOX transcription factors [21].

Recently, some research groups suggested the use of adult stem cells to derive chondrocyte-like cells. In particular, mesenchymal stem cells are considered as good candi- dates for chondrocyte differentiation. In addition, in recent years the interest for perinatal tissues-derived MSCs is increased considering that these cells may be easily sourced [6].

To promote chondrogenic differentiation, MSCs, after expansion in monolayer culture, need a three-dimensional (3D) environment to maintain the chondrocyte phenotype. Different 3D supports were proposed such as polymers, collagen sponges or hydrogels, alginate beads and microspheres [22-25]. Alginate is a linear polysaccaride composed by repeated disaccharides of $\beta$-D-mannuronic-acid and $\alpha$-Lglucuronic acid. In the presence of calcium ions, the alginate can be cross-linked to generate a polymerized hydrogel. In this alginate solution, the cells allocate homogeneously [26]. The porosity of the hydrogel allows the diffusion of large molecules but not passive migration of cells [27].

\section{Perinatal Mesenchymal Stem Cells: Characteristic Fea- tures of WJ-MSCs}

The first isolation of multipotent mesenchymal stromal cells from the bone marrow, was made in the 1970 by Friedenstein [28]. Mesenchymal stem cells (MSCs) are mononuclear, multipotent cells featuring a fibroblastoid morphology. They are defined as immature cells with the ability to self-renew and differentiate towards several cellular types such as osteoblasts, adipocytes and chondrocytes. MSCs grow on plastic surface and therefore can be quickly expanded in vitro for several passages [29]. Some researchers focused their attention on the use of MSCs derived from other easily accessible tissues with higher cellular yields. For example, bone marrow, is currently the common source of MSCs, even if the number of cells results very low [30] and decreases with donor age [31]. Umbilical cord blood, placenta, amniotic membrane and umbilical cord stroma (Wharton's jelly) are some perinatal sources of MSCs. In literature, several studies demonstrated the differentiation ability of these cells in generating all cellular types derived from the three germ layers [32].

Perinatal MSCs expresses a number of surface molecules such as CD105, CD73, CD106 (vascular cellular adhesion molecule-1), CD54 (intercellular adhesional molecule-1), CD44, CD90, CD29 and STRO-1, some cytokine receptors, molecules involved in immune responses such as canonical type I MHC (major histocompatibility complex) as HLA-A. MSCs do not express HLA-DR, a type II MHC, as well as hematopoietic stem cell markers such as CD45 and CD34. Markers such as CD31 (PECAM-1) and von Willenbrand factor (vWF) are specific for endothelial cells $[33,34]$ and we and others demonstrated their absence in WJ-MSCs [35].

In the last years, our research group focused on Wharton's jelly-derived mesenchymal stem cells (WJ-MSCs). Wharton's jelly, also known as intervascular stroma, is the main component of the extracellular matrix of human umbilical cord. It is composed by an amorphous substance rich in glycosamminoglycans (GAG) and proteoglycans, which hosts (in a classical view) two cellular types: myofibroblasts and fibroblast-like cells. The latter are commonly identified as the multipotent mesenchymal stem cells [36]. WJ-MSCs express all markers typical of mesenchymal stem cells but 
express also CD117 (receptor of the stem cell factor). Moreover, our group demonstrated that WJ-MSCs are positive to the expression of some, endodermal markers such as GATA-4, GATA-5, GATA-6, hepatic nuclear factor- $4 \alpha$ $(\mathrm{HNF}-4 \alpha)$, and mesodermal markers such as vimentin, and $\alpha$-smooth muscle actin, suggesting that these cells may differentiate in several cellular types derived from all three germ layers [35, 37]. According to the International Society for Cellular Therapy, WJ-MSCs are multipotent because can differenteiate into osteoblasts, adipocytes and chondrocytes. Various in vitro and in vivo studies demonstrated that $\mathrm{WJ}$ MSCs cultured in a medium supplemented with chondrocyte inducers differentiate into chondrocyte-like cells [1].

\section{Chondrogenic Differentiation by WJ-MSC in Culture and on Scaffolds}

Arufe and colleagues, demonstrated that umbilical cordMSC may differentiate into chondrocyte-like cells when cultured in presence of ascorbic acid, transferrin, dexamethasone, retinoic acid and TGF- $\beta 3$ for up to 46 days. The expression of type I, II, and X collagens, and some other components of chondrocyte matrix such as decorin, galectin1 and chitinase confirmed the acquisition of chondrocyte phenotype [38].

A comparative study carried out by Wang et al., highlighted the ability to differentiate in chondrocyte-like cells on poly-glycolic acid scaffold (PGA) in presence of chondrogenic medium for 6 week by WJ-MSCs and BM-MSCs. The authors observed that WJ-MSCs produced more GAGs and type I collagen than BM-MSCs [39]. A further study confirmed that WJ-MSCs cultured in a chondrogenic medium on PGA scaffold, for 4 weeks, expressed GAGs and type I and II [40].

Recently, it was suggested that WJ-MSCs may differentiate to chondrocyte-like cells if cultured on nanofibrous substrates with a sequential two-steps culture, and differentiated cells expressed GAGs, hyaluronic acid, and some key genes for chondrocyte differentiation process such as SOX9, COMP (cartilage oligomeric matrix protein), collagen type II [41].

\section{Immunomodulatory Properties and Tolerogenic Activity by MSCs}

Several reports described the expression of immunomodulatory molecules by MSCs and in particular by WJMSCs. These data boosted the investigations on the possible interactions between MSC and immune response cells.

The mechanisms underlying immunomodulation by MSCs are different: suppression of $\mathrm{T}$ cell proliferation and dendritic cell differentiation [42], inhibition of B-cells [43], and natural killer cells (NK) proliferation [44], induction of $\mathrm{T}$ cells anergy and stimulation of regulatory $\mathrm{T}$ cells (CD4+CD25+FoxP3+ T regs) [45, 46].

MSCs can modulate the immune system response by cytokines, growth factors, as well as the lack of costimulatory molecules [47]. Release of soluble factors, such as IL-10 (interleukin-10), HLA-G, tumor necrosis factor alpha (TNF- $\alpha$ ), TGF- $\beta$, is normally a results of cross-talk between MSCs and T-lymphocytes [48]. In particular, some reports demonstrated that HLA-G and its soluble form (HLA-G5), were expressed in BM-MSCs and WJ-MSCs [35, $47,49]$. Other molecules belonging to non-canonical type I MHC where investigated by our group, on WJ-MSCs: HLA$\mathrm{E}$ and HLA-F. They are involved in the tolerance process between mother and fetus, and in particular HLA-E plays a key role during selective binding with NK cells $[50,51]$. In addition, we recently demonstrated the expression of CD68 in WJ-MSCs [52].

A recent report, carried out by Spaggiari and co-workers, showed that MSCs are able to inhibit the NK cells proliferation, cytotoxicity and cytokine production, by downregulating the expression of activating NK receptors such as NKp30, NKp44, and NKG2D. This study demonstrated that possible mediators released by MSCs and involved in the inhibition of some NK- cells activities could be prostaglandin-E2 (PGE2) and indoleamine 2,3 dioxigenase (IDO) [44]. According to other works, PGE2, released by MSCs of different origin, can also modulate the activation and proliferation of lymphocyte subset [53].

Recently, some researchers suggested that molecules belonging to the B7 family, with a known co-stimulatory role, may have co-inhibitory role in the T-lymphocytes proliferation. Some reports showed that B7-H3 (CD276), a costimulatory molecule, inhibits human $\mathrm{T}$ cell activation, by decreasing the expression of interleukin-2 (IL-2) [54].

CD80 (B7-1) and CD86 (B7-2) are other two costimulatory molecules of $\mathrm{T}$ cells proliferation, but Sansom and co-workers highlighted that (in absence of CD86), the CD80 mostly exercises an inhibitory effect through binding of CD152 [55]. In conclusion, all these data supported the idea that MSCs could induce immune tolerance in the host. The main aim of the present work was the investigation of the maintenance of expression of immunomodulatory molecules by WJ-MSCs before and after differentiation.

\section{MATERIALS AND METHODS}

\section{Cellular Isolation Protocol of Wharton's Jelly Mesen- chymal Stem Cells}

Isolation protocol was adopted from our previously published data $[35,56]$. All umbilical cords were obtained after mother's informed consent according to tenets of the Declaration of Helsinki and local ethical regulation. After normal vaginal or caesarean delivery, after full-term birth, umbilical cords were stored aseptically in cold saline and cellular isolation was started within six hours from partum. The cords were washed in warm HBSS (Gibco), and then were cut in small pieces about $1.5 \mathrm{~cm}$ length, sectioned longitudinally so that to exhibit the Wharton's jelly under amniotic epithelium. Different incisions, without vessels removal, were made within matrix with sterile scalpel to increase area exposed to the contact with medium composed by DMEM low glucose (Sigma), supplemented with 10\% FBS (fetal bovine serum gold, PAA), 1x NEAA (non-essential aminoacids, Sigma), 1x antibiotics-antimycotics (GIBCO), and $2 \mathrm{mM} \mathrm{L-}$ glutamine (Sigma). This isolation protocol does not use enzymatic activity to dissociate cells from the embedding matrix but is based on cells migratory ability. Cord pieces were left for 15 days with medium changed every second day. 
Table 1. List of antibodies used in the present study.

\begin{tabular}{|c|c|c|c|}
\hline Antigen & Host & Manufacturer & Diluition \\
\hline \hline B7-1 & Mouse & Santa Cruz & $1: 50$ \\
\hline B7-2 & Mouse & Santa Cruz & $1: 200$ \\
\hline B7-H3 & Rabbit & Santa Cruz & $1: 100$ \\
\hline Collagen II & Mouse & Merck Millipore & $1: 50$ \\
\hline CD31 & Mouse & Santa Cruz & $1: 50$ \\
\hline HLA-ABC & Mouse & Santa Cruz & $1: 50$ \\
\hline HLA-DR & Mouse & Santa Cruz & $1: 50$ \\
\hline HLA-E & Mouse & Santa Cruz & $1: 50$ \\
\hline IDO & Mouse & Santa Cruz & $1: 100$ \\
\hline Vimentin & Mouse & \\
\hline
\end{tabular}

Therefore, the slow degradation of the matrix allowed growth factors and signalling molecules to exit from the cord and continuing provide a positive stimulation to the cultured cells.

After 15 days of culture, cells widely adhered to the plastic surface, and were cultured until confluence.

\section{Cell Culturing and Passaging}

After reaching confluence, cells were removed from flasks with Tryple Select (Invitrogen) and were cultured for up to 15 passages. For immunocytochemical analysis, cells were plated in 8-well chamber slides (BD Bioscience) and were used after reaching $90 \%$ confluence. For RNA extraction, cells were cultured either in 6-well tissue culture plates or in $25 \mathrm{~cm}^{2}$ tissue culture flasks (Corning).

\section{Immunohistochemistry}

De-paraffinized sections, were washed with $\mathrm{PBS}-\mathrm{CaCl}_{2}$, followed by addition of $0,3 \%$ hydrogen peroxide to inactivate endogenous peroxidases. After 20 minutes in a blocking solution ( $1 \%$ of bovine serum albumin), they were incubated with specific primary antibodies for 1 hour and 30 minutes at room temperature. After another wash with $\mathrm{PBS}-\mathrm{CaCl}_{2}$, sections were incubated with species-specific secondary antibodies for 10 minutes. Subsequently, streptavidin-peroxidase (DAKO-Cytomation) was added followed by 3.3'diaminobenzidine (DAB chromogenic substrate solution, DAKO). At the end, haematoxylin (DAKO) was used to counter stain the nuclei of the cells.

The antibodies used in the present study, with indications of the working conditions used, are listed in Table $\mathbf{1 .}$

\section{Total RNA Extraction}

Total RNA extraction from Wharton's jelly MSCs was made by RNAspin mini RNA isolation Kit (GE Healthcare), following the manufacturer's instructions.
The RNA extract was stored at $-20^{\circ} \mathrm{C}$ until use. The concentration of RNA extracted was determined by spectrophotometer with a wavelength of $260 \mathrm{~nm}$. Only samples with $\mathrm{A}_{260} / \mathrm{A}_{280}$ ratio over 1.7 were considered useful for the following analyses [57].

\section{RT-PCR (Reverse Transcription Polymerase Chain Re- action)}

Qualitative RT-PCR was performed using Phusion HighFidelity RT-PCR kit (Finnzymes). The reaction comprised a reverse transcription step of 50 minutes at $42 \mathrm{C}^{\circ}$ and an inactivation phase of 5 minute at $92 \mathrm{C}^{\circ}$. The an amplification reaction was performed in a five steps: an initial denaturation of 30 seconds at $98 \mathrm{C}^{\circ}$, followed by another denaturation step of 10 seconds at $98 \mathrm{C}^{\circ}$, the annealing phases of 30 seconds an extension step of 30 seconds at $72 \mathrm{C}^{\circ}$, and final extension for 10 minutes at $72 \mathrm{C}^{\circ}$. See Table 2 for the list of primers used in this study.

\section{Osteogenic Differentiation}

Differentiation of cells was performed by culturing WJMSC at different passages in osteogenic differentiation medium, mainly based on previous reports [35]. Briefly, culture medium was supplemented with $50 \mu \mathrm{M}$ ascorbate-2phosphate (Sigma), $10 \mathrm{mM} \beta$-glycerophosphate (Sigma), 0.1 SM dexamethasone (Sigma), 10\% FCS (PAA), 1x NEAA (non-essential aminoacids) (Sigma) and $1 \%$ antibiotic/antimycotic (Sigma). Cells were cultured in six-well tissue culture plates for 3 weeks and medium was replaced every second day. The formation of cell clusters resembling direct ossification was monitored by phase-contrast microscopy along culturing. Controls included WJ-MSCs cultured in normal growth medium for 3 weeks to monitor the eventual spontaneous formation of bone-like nodules.

\section{Adipogenic Differentiation}

Differentiation of cells was performed by culturing WJMSCs at different passages in adipogenic differentiation medium, mainly based on previous reports [35]: culture me- 
Table 2. List of PCR primers used for the present study.

\begin{tabular}{|c|c|c|c|c|}
\hline Name & $\begin{array}{c}\text { Accession } \\
\text { number }\end{array}$ & $\begin{array}{c}\text { Product } \\
\text { Size }\end{array}$ & Forward Primer & Reverse Primer \\
\hline \hline Actin, beta & NM_001101 & 350 & 5'-AAACTGGAACGGTGAAGGTG-3' & 5'-TCAAGTTGGGGGACAAAAAG-3' \\
\hline B7-H1 & NM_014143 & 271 & 5'-GGTCTGGGACGGTTGGATA-3' & 5'-CCCATGGGATCTTTTGAATTT-3' \\
\hline B7-H3 & NM_025240 & 170 & 5-CCCTCCCTACAGCTCCTACC-3 & 5-CAGCAGGATGACTTGGGAAT-3 \\
\hline B7-H4 & NM_024626 & 273 & 5'-CAGGGAGACACTCCATCACA-3' & 5'-TGAGTTGCACGTTTTTCAGC-3' \\
\hline CD80 & NM_005191 & 259 & 5'-AGGGCCTCCTTAGATCCCTA-3' & 5'-TTAGCTGCCATGAGATGTGC-3' \\
\hline CD86 & NM_175862 & 250 & 5'-TCCTGGCTGAGAGAGGAAGA-3' & 5'-AGACTGCCCCATCCCTTAGT-3' \\
\hline HLA-A & NM_002116 & 262 & 5'-TGGGACTGAGAGGCAAGAGT-3' & 5'-ACAGCTCAGTGCACCATGAA-3' \\
\hline HLA-DR-B1 & NM_002124 & 349 & 5'-GCACAGAGCAAGATGCTGAG-3' & 5'-AGTTGAAGATGAGGCGCTGT-3' \\
\hline HLA-E & NM_005516 & 245 & 5'-CAAGGGCCTCTGAATCTGTC-3' & 5'-CGTGTTAGCCAGGATGGTTT-3' \\
\hline HLA-G & NM_002127 & 287 & 5-GCTCCCACTCCATGAGGTATT-3 & 5-CTGGAGGGTGTGAGAACTGG-3 \\
\hline HLA-F & NM_00109847 & 202 & 5'-TGGAGTTGCTCCGCAGATA-3' & 5' 'TCCACAAGCTCTGTGTCCTG-3' \\
\hline TGFß2 & NM_003231 & 282 & 5' '-TGCGGCCTATTGCTTTAGA-3' & 5'-TTGGGTGTTTTGCCAATGT-3' \\
\hline
\end{tabular}

dium was supplemented with $0.5 \mathrm{mM}$ isobutylmethylxanthine (Sigma), $1 \mu \mathrm{M}$ dexamethasone (Sigma), $10 \mu \mathrm{M}$ insulin (Sigma), $200 \mu \mathrm{M}$ indomethacin (Sigma), 10\% FBS (PAA), 1x NEAA (non-essential aminoacids) (Sigma) and 1\% antibiotic-antimycotic (Sigma).

Cells were cultured in six-well tissue culture plates for 3 weeks, and medium was replaced every second day. The formation of cytoplasmic lipid vacuoles was monitored by phase-contrast microscopy along culturing. Controls included W-MSCs cultured in standard growth medium for 3 weeks to monitor the spontaneous formation of lipid vacuoles.

\section{Chondrogenic Differentiation}

Differentiation of cells was performed by seeding WJMSCs into alginate beads, using slight modifications of previously published protocols [58, 59]. Briefly, WJ-MSCs were resuspended in sodium alginate (Sigma-Aldrich) (4 $\times 10^{6}$ cells $/ \mathrm{ml}$ at a final concentration of $1,2 \%$ sodium alginate in sterile physiologic solution). Beads were formed by slowly dispensing droplets of the alginate cell suspension from a 22-gauge needle syringe into a $100 \mathrm{mM} \mathrm{CaCl} 2$ solution. After washes with $0.15 \mathrm{M} \mathrm{NaCl}$, the beads were rinsed with DMEM. Then, beads were cultured either in standard growth medium (controls) or chondrogenic medium, prepared using published protocols with slight modifications (DMEM supplemented with $1 \%$ FBS, $6.25 \mu \mathrm{g} / \mathrm{ml}$ insulin, 10 $\mathrm{ng} / \mathrm{ml}$ TGF $\beta 1,50 \mathrm{nM}$ ascorbate-2-phosphate, $1 \%$ antibiotic/antimycotic, 1x NEAA) [36]. Beads were maintained in culture for three weeks, with medium changes every second day. For fixation and paraffin embedding, beads were processed as previously described $[58,59]$. The beads were fixed in $4 \%$ paraformaldehyde, $0.1 \mathrm{M}$ cacodylate buffer, $\mathrm{pH} 7.4$, with $10 \mathrm{mM} \mathrm{CaCl}_{2}$ for $4 \mathrm{hrs}$ at $20^{\circ} \mathrm{C}$. and then washed over- night at $4{ }^{\circ} \mathrm{C}$ in $0.1 \mathrm{M}$ cacodylate buffer ( $\mathrm{pH}$ 7.4) containing $50 \mathrm{mM} \mathrm{BaCl}$. The beads were standard dehydrated through alcohols and xylene and embedded in paraffin. Sections $(6 \mu \mathrm{m})$ were processed for histology (Alcian Blue and nuclear fast red staining) and IHC.

\section{Histochemical Staining}

To demonstrate the acquisition of the osteogenic phenotype, the Alizarin Red S staining was performed. Briefly, cells were fixed in $4 \%$ paraformaldehyde and stained with $1 \%$ solution of Alizarin Red S (Sigma). Stained cells were rinsed with water for three times to remove excess stain, and then photographed at the photomicroscope.

To demonstrate the adipogenic differentiation, cells were stained with Oil Red O (Sigma), and photographed at the photomicroscope. After medium aspiration, a brief wash was performed with PBS. Cells were fixed with $10 \%$ formalin (Sigma) for $30 \mathrm{~min}$ at room temperature, followed by subsequent washes with distilled water and $60 \%$ isopropanol. Oil Red $\mathrm{O}$ working solution was added to the cells for $5 \mathrm{~min}$, followed by four washes $(5 \mathrm{~min}$ each) with distilled water. The wells were viewed and photographed using an inverted phase-contrast microscope. Following a further step of counterstaining (Meyer's haematoxylin, 1 minute), lipid vacuoles appeared red and nuclei appeared blue. To demonstrate the acquisition of the chondrogenic phenotype, the alcian blue with nuclear fast red staining was performed. Cells cultured in alginate beads were formalin-fixed and paraffin embedded using standard protocols. Sections were de-paraffinized and hydrated to distilled water, then Alcian Blue (SigmaAldrich) solution (1\% Alcian Blue $8 \mathrm{GX}$ in $3 \%$ acetic acid, $\mathrm{pH}$ 2.5) was added for 30 minutes. After washing, nuclei were counterstained with nuclear fast red (Sigma-Aldrich) 

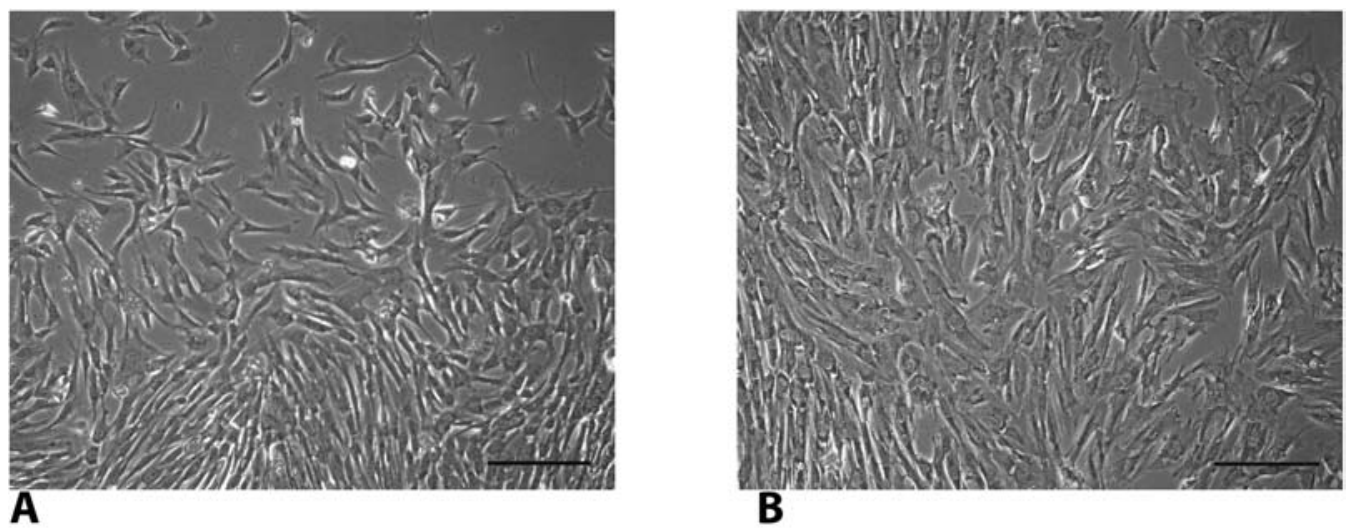

B
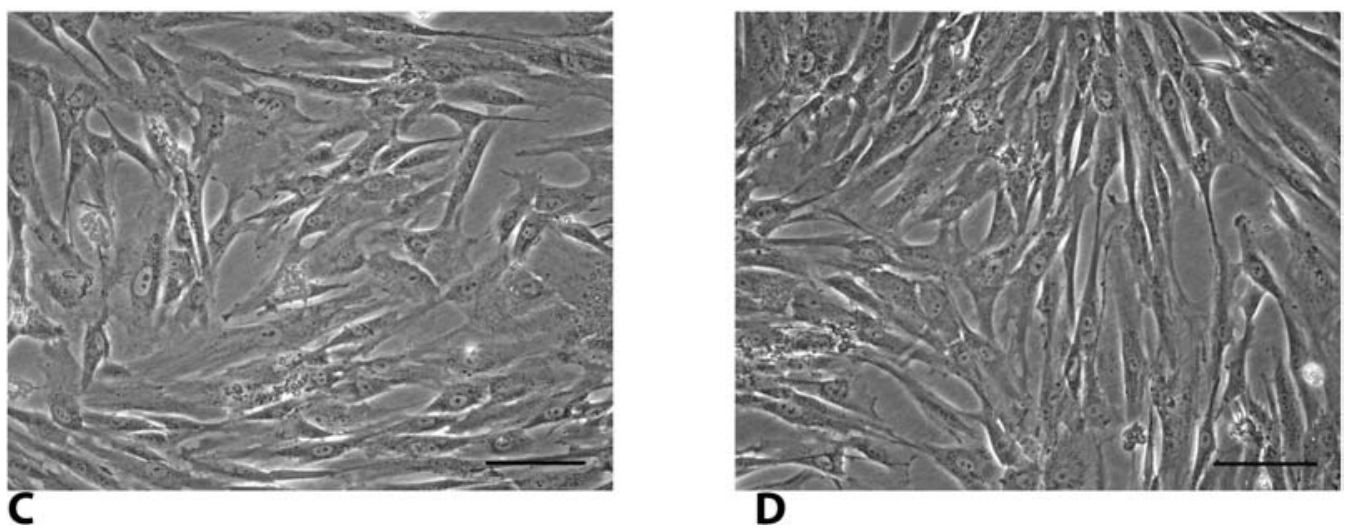

Fig. (1). Light microscopic micrographs of different WJ-MSCs populations in monolayer culture. Cultured cells assumed a polymorphic, fibrobroblast-like morphology, which was maintained throughout the passaging process. The panels show: cells at passage 1, prior to reach confluence $(\mathbf{A})$; confluent cells at passage 1 (B); confluent monolayer at passage 1 (C, D). Magnification x20. Bar: $100 \mu$.

solution $(0.1 \%)$. Sections were then dehydrated and mounted for observation (not shown).

\section{RESULTS}

\section{Cellular Isolation of WJ-MSCs}

The isolation protocol of WJ-MSCs which we developed allows to reproducibly isolate and expand plastic-adherent cells starting from tissue explants. During 15 days, WJMSCs exit from samples and migrate to adhere to the substrate, therefore the slow degradation of the matrix determine a continue stimulation for cells by growth factor and signalling molecules action. WJ-MSCs cultured in standard growth medium showed fibroblastoid morphology at different confluence states. As visible in Fig. (1) the typical mesenchymal morphology of WJ-MSCs isolated from different samples is maintained at different passages.

Confluent cells were routinely splitted and maintained in culture up to $15^{\text {th }}$ passage, with a mean population doubling time of 7.5 days. To confirm the long-term storability and the ability to survive deep freezing, the cultured cells were freezed and stored in liquid nitrogen at different passages and subsequently were defrosted and cultured (data not shown). Standard immunocytochemical and molecular analyses were routinely performed on freshly isolated cells to assess the expression of typical mesenchymal markers and the absence of haematopoietic/endothelial markers (data not shown).

\section{Tri-Lineage Differentiation of WJ-MSCs}

According to the general consensus, MSCs are considered multiopotent stem cells since they can be differentiated into almost three different cell types: osteocytes, adipocytes and chondroblasts.

For osteogenic differentiation, WJ-MSCs were cultured in a maturation medium for three weeks. For the same time, control cells were cultured in standard growth medium. The process of osteoblast differentiation was assessed by Alizarin Red S staining: as visible in Fig. (2A, B), control cells were negative to the staining, while the differentiated cells showed a red staining, indicating of the accumulation of extracellular calcium-containing deposits. Moreover, the control cells, cultured in a standard growth medium, maintained the fibroblastoid morphology, while the cells induced to osteogenic differentiation, showed the formation of cellular aggregates, similar to bone nodules.

To demonstrate that WJ-MSCs may differentate towards adipocyte-like cells, we cultured our cells in a medium supplemented with adipogenic inducers and in a control medium for three weeks. By phase-contrast microscopy, it possible to observe in Fig. (2C, D) the presence of multiple intracellular 


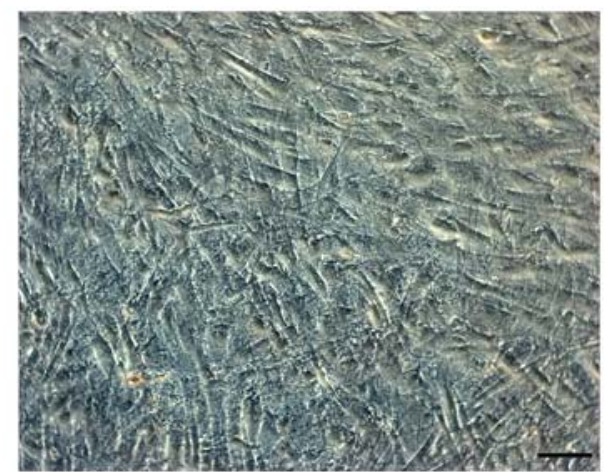

A

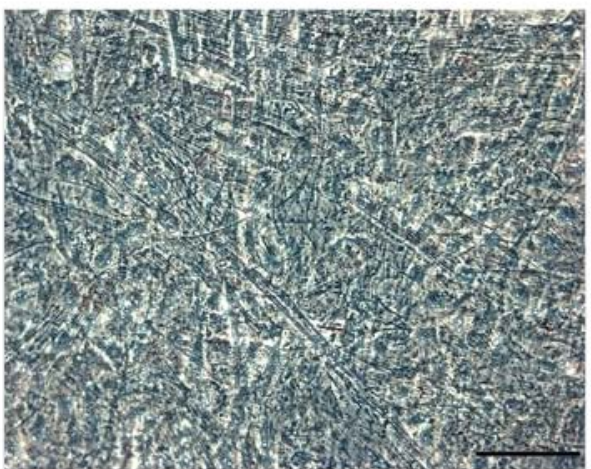

C

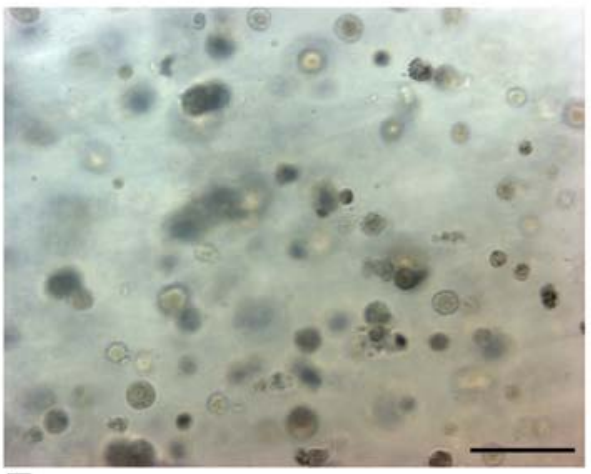

E

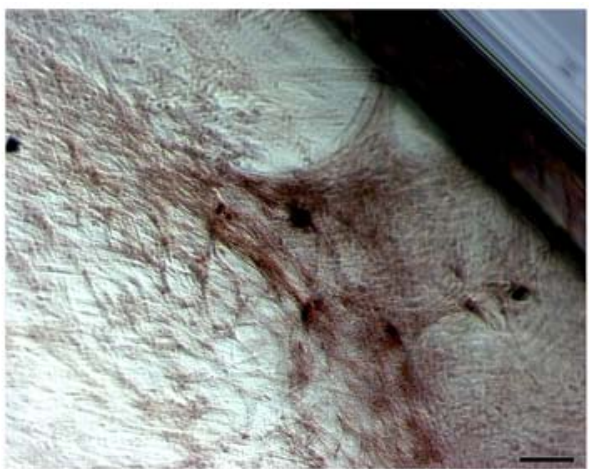

B

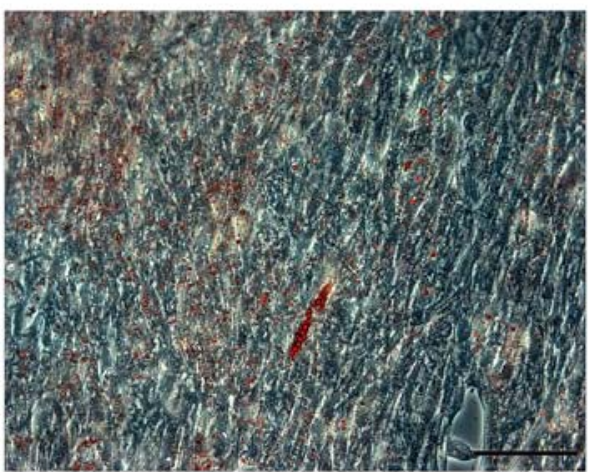

D

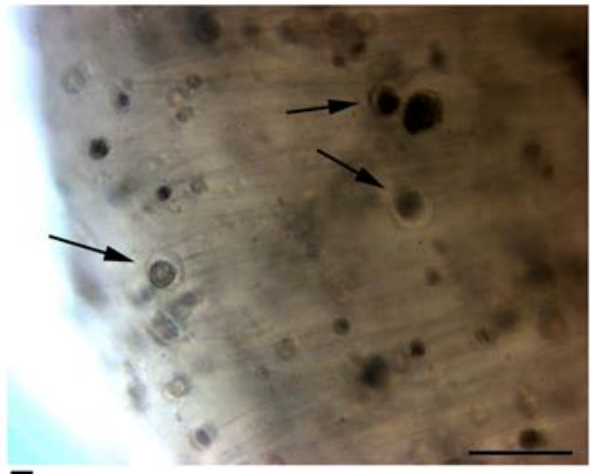

$\mathbf{F}$

Fig. (2). Light microscopic demonstration of bone tissue formation by WJ-MSCs following osteogenic differentiation. WJ-MSCs cultured in osteogenic medium assume a cuboidal shape with formation and deposit of a mineralized matrix assessed by Alizarin Red S staining (B), with respect to fibroblastoid, staining-negative control cells (A). Adipogenic-like cells feature the presence of neutral lipid vacuoles, evidenced by Oil red staining (D), which are absent in control cells (C). WJ-MSCs cultured for 3 weeks in chondrogenic medium, in alginate matrix showed morphological variations (appearance of rounded lacunae, indicated by arrows) (F) with respect to control cells (E). Magnifi-

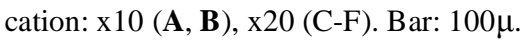

vacuoles, only in differentiated cells, as demonstrated by Oil Red O staining, which allowed to highlight the presence of multiple neutral lipid vacuoles of different sizes in adipocyte-like cells, resembling multivacuolar adipocytes of brown fat. As expected, control cells were negative to this staining.

For chondrogenic differentiation, we cultured cells, after seeding in alginate matrix, in presence of a medium supplemented with chondrogenic inducers and, for controls, in a standard growth medium for three weeks, as we reported previously [59]. As visible in Fig. (2F), only differentiated cells featured the expected formation of lacunae, while con- trol cells do not (Fig. 2E). The acquisition of a chondrogenic phenotype was also confirmed by immunocytochemical analysis (see below), by evaluating the expression of type II collagen, which is characteristically expressed in cartilage.

\section{Expression of Immunomodulatory Molecules in Control and Chondrogenic-Like Cells, Cultured in Alginate Ma- trix}

Since one of the main features of MSCs is the immune modulation of lymphocyte activity in vitro and in vivo, the maintenance of these characteristics by differentiated cells clearly deserves further investigation. Few papers are present 


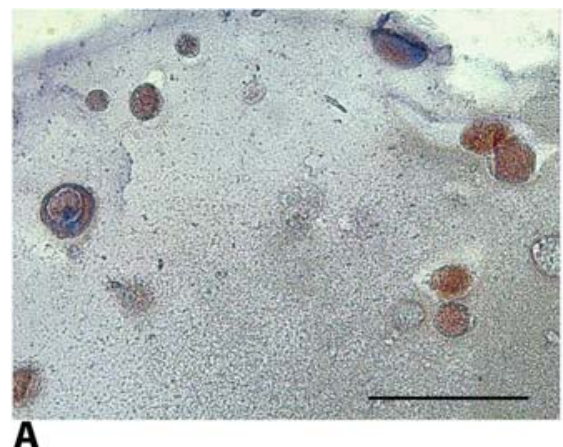

A
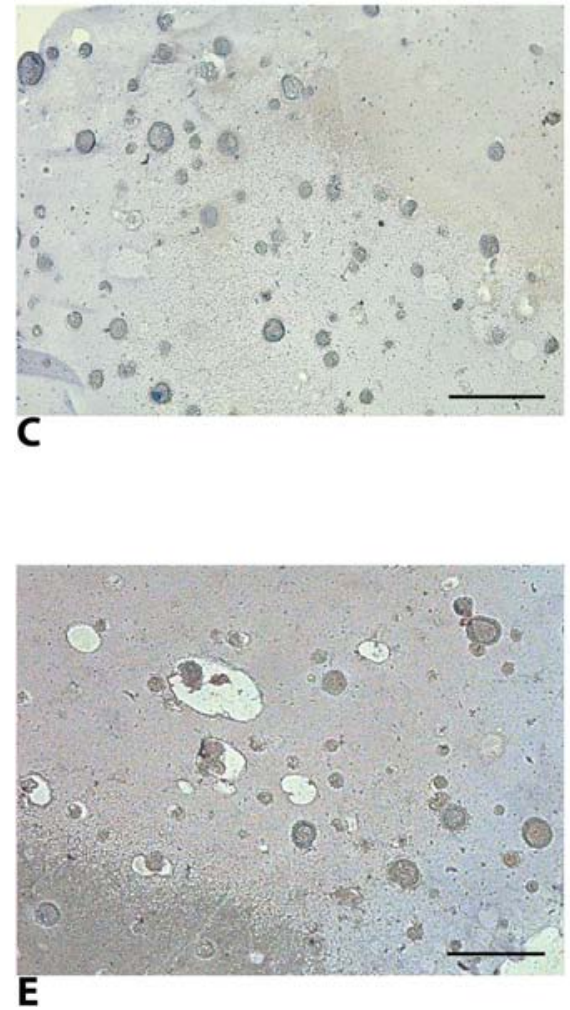

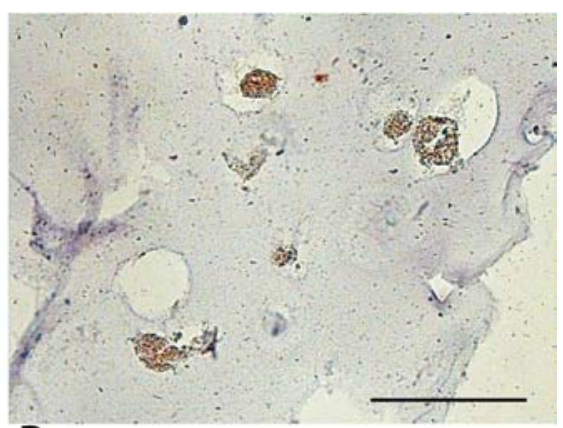

B
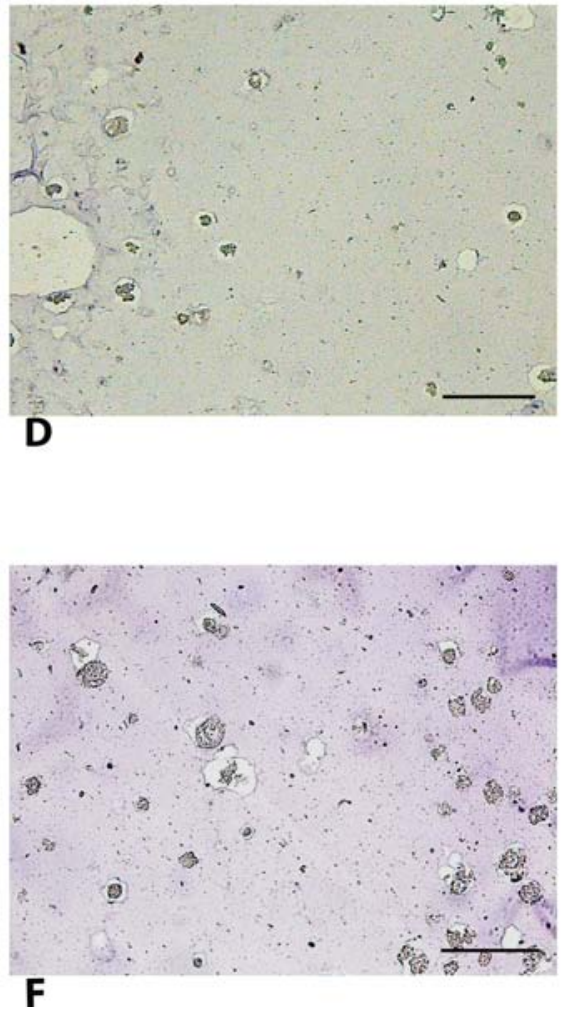

Fig. (3). Representative panels of immunohistochemistry detection of immune-related molecules by WJ-MSCs cultured in alginate matrix and induced to differentiate in presence of chondrogenic medium. Control cells were cultured in a standard growth medium. HLA-A/B/C was expressed in both control $(\mathbf{A})$ and chondrogenic-like cells $(\mathbf{B})$, while HLA-DR was not detectable in any condition $(\mathbf{C}$, D). Control cells showed positivity for B7-H3 (CD276) (E), with the light staining which was also present in differentiated cells (F). Magnification x 40 (A, B); x20 (C-F). Bar: $100 \mu$.

in literature dealing with the immune features of differentiated cells, with contrasting results between the osteogenic and chondrogenic model. In addition, the number of immune-related molecules investigated remains low, often limited to the MHC molecules and classical B7 costimulators (CD80 and CD86).

Therefore, to extend the previous reports and try to elucidate whether the expression of immunomodulatory molecules may be a feature only of undifferentiated WJ-MSCs, we evaluated the expression of different immune molecules also in differentiated cells and in particular in chondrogeniclike cells. Immunohistochemistry analysis on alginatecultured cells confirmed the expression of type I MHC such
(HLA-A-B-C) and the lack of HLA-DR, a type II MHC, both in undifferentiated and differentiated cells Fig. (3), panels A-D). According to recent data in literature [56], also WJ-MSCs expressed HLA-E, a non-classical type I MHC molecule involved during tolerance-induction processes and in particular in the selective binding with NK cells. Even if WJ-MSCs do express HLA-E when cultured in standard conditions, as shown below for the osteogenic and adipogenic differentiation experiments, chondrogenic differentiation shows that neither alginate-seeded undifferentiated cells, nor differentiated ones, did express this marker at the protein level. We may hypothesize that the three-dimensional alginate matrix influences the cellular behaviour so that the expression of some factors is lost even in undifferentiated cells. 


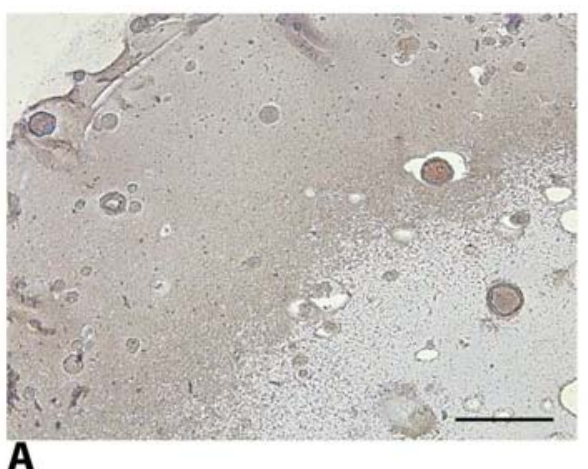

A

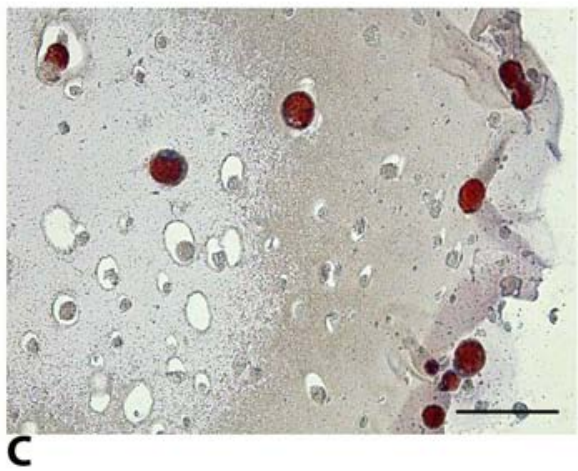

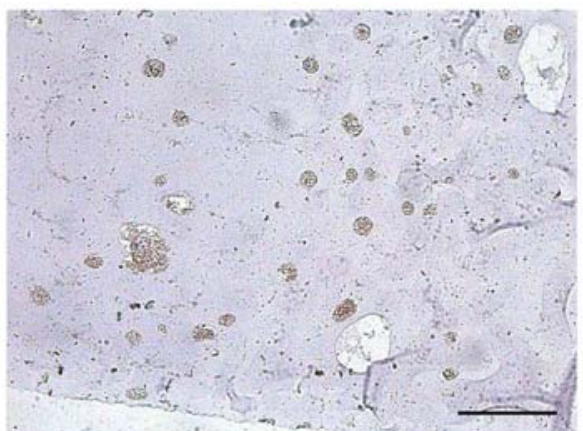

B

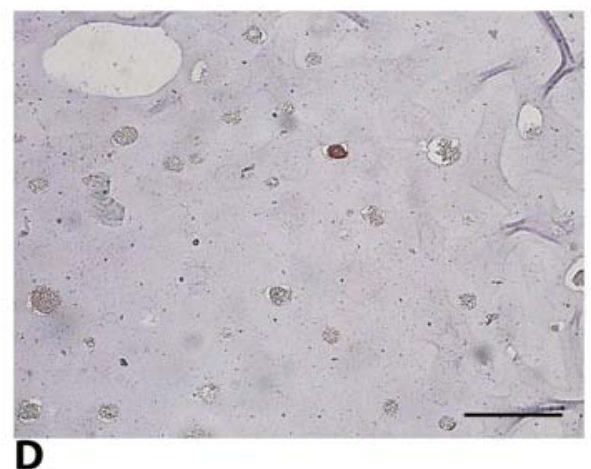

Fig. (4). Immunohistochemical demonstration of collagen type II expression by chondrogenic-differentiated WJ-MSCs. Cells cultured in alginate matrix with standard growth medium did not form lacunae around cells, and did express both type II collagen (A) and vimentin (C). Alginate-seeded cells grown in differentiation medium showed the appearance of pericellular lacunae, and maintained the expression of both

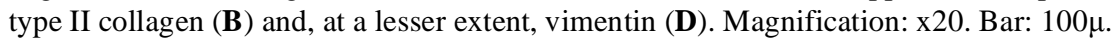

In our opinion, further research is needed to better clarify this issue in the chondrogenic differentiation model. Another immunomodulatory molecule which has been demonstrated to be expressed by MSCs is IDO, an enzyme involved in the tryptophan metabolism, an essential aminoacid for lymphocyte proliferation (see Table 3). Also for this molecule, its expression in WJ-MSCs was demonstrated in our laboratory (Anzalone et al., manuscript in preparation). However, as observed for HLA-E, alginate embedding seems to block the expression of IDO at the protein level in both undifferentiated and differentiated cells.

The expression of molecules belonging to the B7 superfamily is of critical importance for their role as costimulators in immune processes. MSCs are mainly negative for classical members of this family, as B7-1 (CD80) and B7-2 (CD86). As shown in Table 3, both molecules were absent in both control and chondrogenic cells, therefore confirming the maintenance of the immune asset of these molecules after differentiation. In addition, for the first time in WJ-MSC, we demonstrated in both undifferentiated and chondrogeniclike cells the presence of B7-H3 (CD276), (Fig. 3E, F). For this co-stimulatory molecule also co-inhibitory roles have been suggested [49]. Immunohistochemical detection allowed to confirm the mesenchymal phenotype by these cells, highlighting the expression of vimentin, an intermediate filament found in cells of mesenchymal origin (Fig. 4C, D). To confirm the acquisition of chondrogenic phenotype by
WJ-MSCs, we evaluated the expression of a cartilagespecific protein, type II collagen, as shown in Fig. $(\mathbf{4 A}, \mathbf{B})$. According general consensus MSCs population do not express haematopoietic stem cells markers, and here we showed the lack expression of CD31 both in undifferentiated and differentiated WJ-MSCs. (see Table 3).

Expression of Immunomodulatory Molecules in Osteogenic and Adipogenic Control and Differentiated Cells

A further comparative analysis was carried out in parallel between WJ-MSCs and differentiated adipogenic and osteogenic-like cells by qualitative RT-PCR.

As shown in Table 4, WJ-MSCs differentiated towards osteogenic and adipogenic lineages do maintain the expression of some immune-related molecules compared to control cells. In fact, as also shown in Fig. (5), the non-classical type I MHC molecules HLA-E, HLA-F and HLA-G, are expressed in both control and differentiated cells. This constitutes, to the best of our knowledge, the first evidence in MSC-derived differentiated cells. Both undifferentiated and differentiated cells the lacked the expression of HLA-DR as shown in Table 4 and in Fig. (5). HLA-F and HLA-G are two non canonical class Ib MHC molecules involved during the establishment of tolerance processes between mother and fetus. Molecular biology analysis further confirmed the expression of B7-H3 in both undifferentiated and differentiate cells. (see Table 4). Since other reports highlighted the pres- 
Table 3. Immunohistochemistry results of markers expression by undifferentiated and chondrogenic-like cells. Results of the immunohistochemistry analysis are represented semiquantitatively.

\begin{tabular}{|c|c|c|}
\hline Antigen & Control & Differentiated \\
\hline \hline B7-H3 & ++ & ++ \\
\hline B7-1 & - & - \\
\hline B7-2 & - & - \\
\hline CD31 & - & ++ \\
\hline Collagen II & + & + \\
\hline HLA-ABC & ++ & - \\
\hline HLA-DR & - & - \\
\hline HLA-E & - & - \\
\hline IDO & - & + \\
\hline Vimentin & ++ & \\
\hline
\end{tabular}

ence in BM-MSCs of other molecules belonging to B7 family, known to have also a co-inhibitory role, such as B7-H1 and B7-H4, we wanted to assess their expression in $\mathrm{WJ}-$ MSCs. As detailed in table 4, both undifferentiated and differentiated cells do not express these molecules.

The presented data collectively demonstrate that WJMSCs maintain the expression of immune-related molecules in both undifferentiated and differentiated state, therefore suggesting that these cells may be considered good candidates for clinical applications.

\section{DISCUSSION}

In the last years, musculoskeletal and arthritic disorders are increasingly viewed as one of the main causes of disability in the world. OA and RA are now recognized, by World Health Organization, as the musculoskeletal conditions that induce major health troubles [60].

Articular cartilage is the main target of these disorders which heavily affect its structure. Chondrocytes represent the only cellular type of cartilage. They are plunged in the matrix and are fed thanks to diffusion processes due to the avascularity of this tissue. For this reason, the cartilage regeneration and repair processes are very slow. Thanks to the differentiative capacity of mesenchymal stem cells, there is accumulating evidence for their use in cartilage tissue engineering and musculoskeletal tissue regeneration [2]. Articular cartilage is avascular while bone is very well vascularized: thanks to the presence of some capillaries in subchondral bone at the cartilagine-bone interface, chondrocytes receive nutrients and can perform gas exchange. A recent work suggested the use of a vascularized tissue engineered construct obtained by presence of tissue progenitor and vascular progenitor cells into biocompatible scaffold [61]. Particular interest was demonstrated in the use of specific media to support proliferation by MSCs and their transdifferentiation process. Some studies showed that hypoxia can induce chondrogenesis and chondrogenic differentiation of MSCs [62-64]. Further reports highlighted the use of a bioreactor with co-culture of MSCs and other stem cells to study the culture and mechanical stimulation [65]. Emerging data showed that MSCs could modulate innate and adaptive immunity by several mechanisms, therefore reinforcing the concept of their use for cellular therapy. MSCs inhibit T-

Table 4. RT-PCR results of immune molecules expression by control and differentiated cells (adipogenic-like cells and osteogeniclike cells). Results of molecular analysis are represented qualitatively.

\begin{tabular}{|l|c|c|c|c|}
\hline Immune Molecules & Control Cells & Osteogenic-Like Cells & Control Cells & Adipocyte-Like Cells \\
\hline \hline B7-H1 & - & - & - & - \\
\hline B7-H3 & + & + & + & + \\
\hline B7-H4 & - & - & - & - \\
\hline CD80 & - & - & - & - \\
\hline CD86 & - & + & + & - \\
\hline HLA-A & + & - & - & + \\
\hline HLA-DR & - & + & + & + \\
\hline HLA-E & + & + & + & + \\
\hline HLA-F & + & + & + & + \\
\hline HLA-G & + & + & + \\
\hline TGFB2 & + & + & + \\
\hline
\end{tabular}




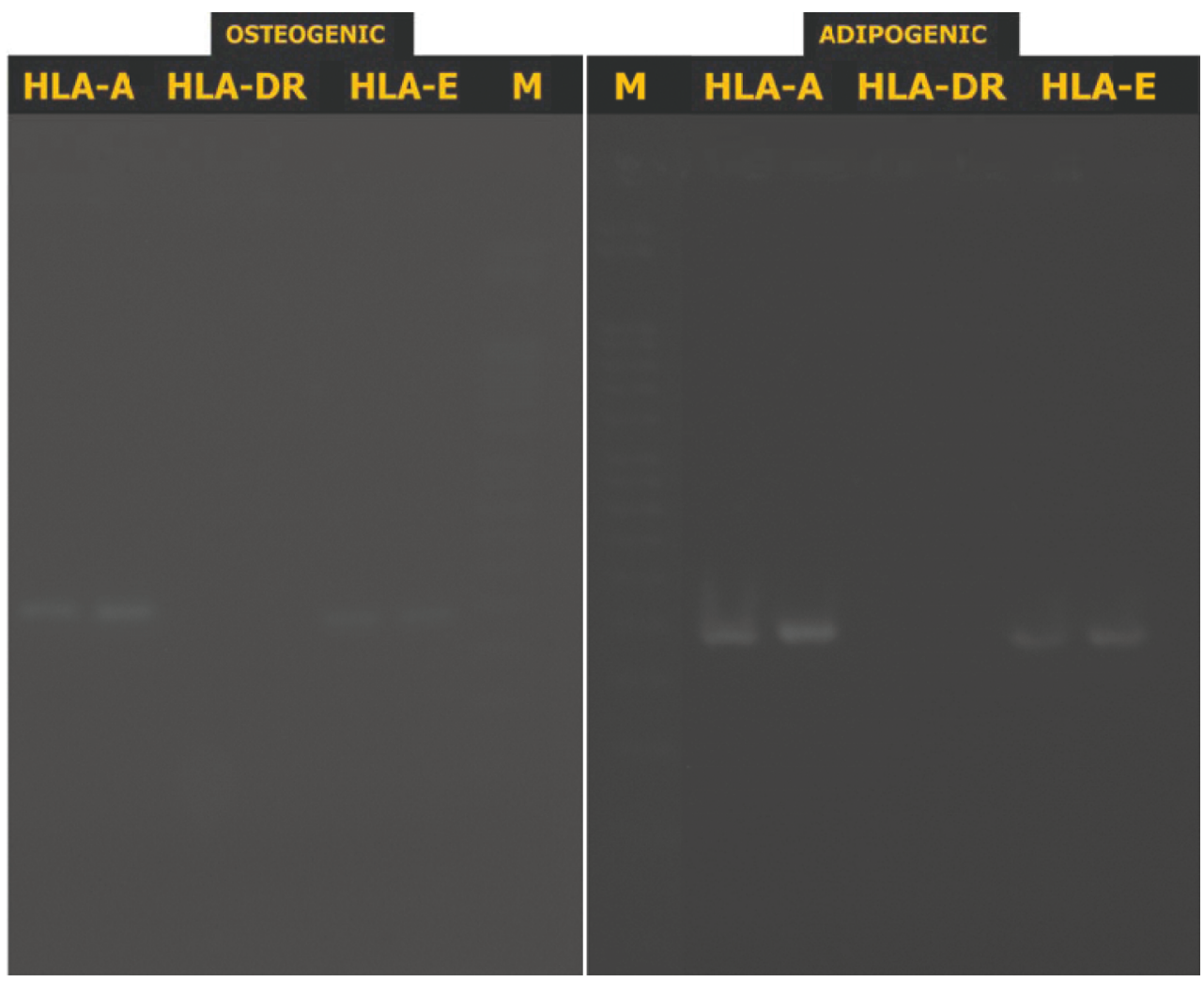

Fig. (5). Representative panels of RT-PCR analysis of immune molecules expression in WJ-MSC subjected to adipogenic or osteogenic differentiation. WJ-MSC cultured for three weeks in presence of osteogenic and adipogenic medium showed the expression of HLA-A and HLA-E, while HLA-DR was not detectable. Control WJ-MSC cultured for three weeks in a standard growth medium show the same pattern of immune molecules expression. M: $50 \mathrm{bp}$ ladder. Left lanes are referred to controls and right lane sto differentiated cells, for any molecole considered.

lymphocyte proliferation and activation by soluble factors such as TGF- $\beta$ PGE2, HGF and IDO [66]. In particular, MSCs could decrease IFN- $\gamma$ production and could increase the IL-4 expression, determining a switch from proinflammatory state to anti-inflammatory one [67].

In the present paper, we aimed to determine the expression, both in undifferentiated and differentiated cells, of some of the major immune-related molecules which have been suggested as responsible of MSCs immune privilege.

T- cell anergy is mechanism by which MSCs induce immunosuppression: some authors demonstrated that the lack expression of two co-stimulatory molecules such as CD80 (B7-1) and CD86 (B7-2) by MSCs could induce an anergy state in $\mathrm{T}$ cells [68]. In our report, we showed by immunohistochemistry analysis that both undifferentiated and differentiated WJ-MSCs do not express the two B7 molecules. Recent reports indicated that other members of the B7family, namely B7-H1, B7-H3, B7-H4 may have promising co-inhibitory roles in addition to known co-stimulatory roles. Previously, the expression of B7-H1 and B7-H4 has been demonstrated in BM-MSCs [50]. In contrast, our results showed the lack expression of these two molecules in both undifferentiated and differentiated WJ-MSCs. On the contrary, we demonstrated that our cells do express B7-H3 (CD276) at both the protein and RNA level. The expression of such marker seems to be unaffected by the differentiation protocol applied, and recalls what we just observed in human heart-derived MSCs, which are the first class of adult MSCs in which CD276 expression has been characterized [59].

Classical and non-classical class I MHC molecules are increasingly being considered as promising molecules for the global immune privilege of mesenchymal stem cells. In literature, some reports highlighted the capacity by MSCs to determine a tolerance process by inducing the proliferation of regulatory $\mathrm{T}$ cells ( $\mathrm{T}$ regs) by release of the HLA-G isoform HLA-G5. In our experiments, RT-PCR analysis allowed to highlight the expression of HLA-G mRNA in control cells and osteogenic and adipogenic differentiated cells. Other class Ib MHC molecules are HLA-E and HLA-F, produced by trophoblast cells together with EPF (early pregnancy factor) [69]. All these molecules have been involved in the tolerance process between mother and fetus. The expression of these molecules in MSCs has been highlighted in heart-derived MSCs [59], and we wanted to better detail their presence also in WJ-MSCs. We demonstrated by RTPCR analysis that WJ-MSCs express both these class Ib $\mathrm{MHC}$, in both undifferentiated and differentiated state. This is the first report highlighting the expression of HLA-F in WJ-MSCs.

Collectively, these data may provide a further point in the characterization of differentiated cells not only on the basis of the expression of desired markers of the mature cytotype, 
but also for the maintenance of the immunomodulatory properties of naïve cells, which may further promote the reparative action of these cells if used in regenerative medicine applications. A number of diseases which in their final stages require organ transplant or cellular therapy, derive from or are accompanied by, an unbalance in the organ inflammatory or immune state. To this regard, the use of a cellular therapy vehicle which may provide both organ recellularization and restoration of a physiological microenvironment, may be a further benefit for patients. In addition, as MSCs are globally recognized for their immune privilege, which allows to evade the host immune response also in allogeneic settings, the possibility that also differentiated cells may maintain this feature deserves further research and in vivo applications for the increasing potential beneficial outcomes it can reserve. Literature reports did suggest that the chondrogenic differentiation process often fails in maintaining the immunomodulatory features of undifferentiated cells, when compared to the adipogenic or osteogenic differentiations [70-72]. Our present data suggest that for some antigens (as HLA-E), the alginate-embedding protocol may result in a phenotypycal switch also in the control cells. However, the positive correlation observed for the other MHC molecules, and the B7 costimulators monitored, strongly point to the maintenance of immune-related molecules as a global feature of differentiated WJ-MSCs.

\section{REFERENCE}

Our data strongly support the concept of WJ-MSCs as a reliable and promising option for cellular therapy, in the regenerative and reparative medicine field.

\section{CONFLICT OF INTEREST}

Dr. La Rocca is member of the Scientific Board of Auxocell Laboratories, Inc. The funders had no role in article design, data collection, decision to publish, or preparation of the manuscript.

\section{ACKNOWLEDGEMENTS}

Authors' results referred to in this paper were in part supported by University of Palermo grants (ex 60\% 2007) to RA, FF, GLR and Istituto Euro-Mediterraneo di Scienza e Tecnologia (IEMEST) to GLR.

\section{REFERENCES}

[1] Lo Iacono M, Anzalone R, Corrao S, et al. Perinatal and Wharton's Jelly-derived mesenchymal stem cells in cartilage regenerative medicine and tissue engineering strategies. Open Tissue Eng Regen Med J 2011; 4:72-81

[2] Mobasheri A, Shakibaei M. Applications of mesenchymal stem cells in cartilage tissue engineering-part 1. Recent Pat Regen Med 2011; 1: 30-41.

[3] Buckwalter JA, Mankin HJ. Articular cartilage: Tissue design and chondrocyte-matrix interactions. Instr Course Lect 1998; 47: 47786

[4] Kuettner KE, Aydelotte MB, Thonar EJ. Articular cartilage matrix and structure: A minireview. J Rheumatol Suppl 1991; 27: 46-8

[5] Ogawa R. Recent patents on stem cell-mediated cartilage regeneration and repair. Recent Pat Regen Med 2011; 1: 118-22

[6] Buckwalter JA, Mankin HJ. Articular cartilage repair and transplantation. Arthritis Rheum 1998; 41: 1331-42.
Kim AJ, Adkisson HD, Wendland M, et al. Juvenile chondrocytes may facilitate disc repair. Open Tissue Eng Regen Med J 2010; 3 : 28-35.

[8] Barna M, Niswander L. Visualization of cartilage formation: insight into cellular properties of skeletal progenitors and chondrodysplasia syndromes. Dev Cell 2007; 12: 931-41.

[9] Ng LJ, Tam PP, Cheah, KS. Preferential expression of alternatively spliced mRNAs encoding type II procollagen with a cysteine-rich amino-propeptide in differentiating cartilage and nonchondrogenic tissues during early mouse development. Dev Biol 1993; 159: 40317.

[10] Sandell LJ, Morris N, Robbins JR, Goldring MB. Alternatively spliced type II procollagen mRNAs define distinct populations of cells during vertebral development: differential expression of the amino-propeptide. J Cell Biol 1991; 114: 1307-19.

[11] Oberlender SA, Tuan RS. Expression and functional involvement of $\mathrm{N}$-cadheri in embryonic limb chondrogenesis. Development 1994; 120: 177-87.

[12] Widelitz RB, Jiang TX, Murray BA, Chuong CM. Adhesion molecules in skeletogenesis: II. Neural cell adhesion molecules mediate precartilaginous mesenchymal condensations and enhance chondrogenesis. J Cell Physiol 1993; 156: 399-411.

[13] Mackie EJ, Thesleff I, Chiquet-Ehrismann R. Tenascin is associated with chondrogenic and osteogenic differentiation in vivo and promotes chondrogenesis in vitro. J Cell Biol 1987; 105: 2569-79.

[14] Akiyama H, Chaboissier MC, Martin JF, Schedl A, de Crombrugghe B. The transcription factor Sox 9 has essential roles in successive steps of the chondrocyte differentiation pathway and is required for expression of Sox 5 and Sox6. Genes Dev 2002; 16: 2813-28.

[15] Zuscik J, Hilton MJ, Zhang X, Chen D, O'Keefe RJ. Regulation of chondrogenesis and chondrocyte differentiation by stress. J Clin Invest 2008; 118: 429-38

[16] Sandell LJ, Morris N, Robbins JR, Goldring MB. Alternatively spliced type II procollagen mRNAs define distinct populations of cells during vertebral development: differential expression of the amino-propeptide. J Cell Biol 1991; 114: 1307-19

[17] Bobick BE, Chen FH, Le AM, Tuan RS. Regulation of the chondrogenic phenotype in culture. Birth Defects Res C Embryo Today 2009; 87:351-71

[18] Freyria AM, Mallein-Gerin F. Chondrocytes or adult stem cells for cartilage repair: The indisputable role of growth factors. Injury 2012; 43: 259-65.

[19] Gouttenoire J, Bougault C, Aubert-Foucher E, et al. BMP-2 and TGF-beta1 differentially control expression of type II procollagen and alpha 10 and alpha 11 integrins in mouse chondrocytes. Eur $\mathbf{J}$ Cell Biol 2010; 89: 307-14.

[20] Valcourt U, Gouttenoire J, Aubert-Foucher E, et al. Alternative splicing of type II procollagen pre-mRNA in chondrocytes is oppositely regulated by BMP-2 and TGF-beta1. FEBS Lett 2003; 545: 115-9.

[21] Hautier A, Salentey V, Aubert-Foucher E, et al. Bone morphogenetic protein-2 stimulates chondrogenic expression in human nasal chondrocytes expanded in vitro. Growth Factors 2008; 26: 201-11.

[22] Hui TY, Cheung KM, Cheung WL, et al. In vitro chondrogenic differentiation of human mesenchymal stem cells in collagen microspheres: influence of cell seeding density and collagen concentration. Biomaterials 2008; 29: 3201-12.

[23] Noth U, Rackwitz L, Heymer A, et al. Chondrogenic differentiation of human mesenchymal stem cells in collagen type I hydrogels. J Biomed Mater Res A 2007; 83:626-35

[24] Pittenger MF, Mackay AM, Beck SC, et al. Multilineage potential of adult human mesenchymal stem cells. Science 1999; 284: 143-7.

[25] Shen B, Wei A, Tao H, et al. BMP-2 enhances TGF-beta3mediated chondrogenic differentiation of human bone marrow multipotent mesenchymal stromal cells in alginate bead culture. Tissue Eng Part A 2009; 15: 1311-20.

[26] Kavalkovich KW, Boynton RE, Murphy MJ, Barry F. Chondrogenic differentiation of human mesenchymal stem cells within an alginate layer culture system. In vitro Cell and Dev Biol-Animal 2002; 38: 457-66. 
[27] Guo JF, Jourdian GW, MacCallum DK. Culture and growth characteristics of chondrocytes encapsulated in alginate beads. Connect Tissue Res 1989; 19(suppl. 2-4): 277-97.

[28] Friedenstein AJ, Gorskaya JF, Kulagina NN. Fibroblast precursors in normal and irradiated mouse hematopoietic organs. Experimental Hematology 1976; 4: 267-74.

[29] Krampera M, Pasini A, Pizzolo G, Cosmi L, Romagnani S, Annunziato F. Regenerative and immunomodulatory potential of mesenchymal stem cells. Curr Opin Pharmacol 2006; 6: 435-41

[30] Fukuchi Y, Nakajima H, Sugiyama D, Hirose I, Kitamura T, Tsuji $\mathrm{K}$. Human placenta derived cells have mesenchymal stem/ progenitor cell potential. Stem Cells 2004; 22: 649-58

[31] Rao MS, Mattson MP. Stem cells and aging: Expanding the possibilities. Mech Aging Dev 2001; 122: 713-34.

[32] Taghizadeh RR, Cetrulo KJ, Cetrulo CL. Wharton's Jelly stem cells: future clinical applications. Placenta 2011; 32 Suppl 4: S3115.

[33] La Rocca G, Di Stefano A, Eleuteri E, et al. Oxidative stress induces myeloperoxidase expression in endocardial endothelial cells from patients with chronic heart failure. Basic Res Cardiol 2009; 104: 307-20.

[34] Anzalone R, La Rocca G, Di Stefano A, et al. Role of endothelial cell stress in the pathogenesis of chronic heart failure. Front Biosci 2009; 14: 2238-47.

[35] La Rocca G, Anzalone R, Corrao S, et al. Isolation and characterization of Oct-4+/HLA-G+ mesenchymal stem cells from human umbilical cord matrix: differentiation potential and detection of new markers. Histochem Cell Biol 2009; 131: 267-282

[36] Can A, Karahuseyinoglu S. Human umbilical cord stroma with regard to the Source of foetus-derived stem cells. Stem Cells 2007; 25: $2886-95$

[37] La Rocca G. Connecting the dots: the promises of Wharton's jelly mesenchymal stem cells for tissue repair and regeneration. Open Tissue Eng Regen Med J 2011; 4: 3-5.

[38] Arufe MC, De la Fuente A, Mateos J, et al. Analysis of the chondrogenic potential and secretome of mesenchymal stem cells derived from human umbilical cord stroma. Stem Cells Dev 2011; 20: 1199-212.

[39] Wang L, Tran I, Seshareddy K, Weiss ML, Detamore MS. A comparison of human bone marrow-derived mesenchymal stem cells and human umbilical cord-derived mesenchymal stromal cells for cartilage tissue engineering. Tissue Eng Part A 2009; 15: 2259-66.

[40] Wang L, Seshareddy K, Weiss ML, Detamore MS. Effect of initial seeding density on human umbilical cord mesenchymal stromal Cells for fibrocartilage tissue engineering. Tissue Eng Part A 2009; 15: 1009-17.

[41] Fong C-Y, Subramanian A, Gauthaman K, et al. Human umbilical cord Wharton's jelly stem cells undergo enhanced chondrogenic differentiation when grown on nanofibrous scaffolds and in a sequential two-stage culture medium environment. Stem Cell Rev Rep 2012; 8: 195-209.

[42] Vija L, Fargec, D, Gautier JF, et al. Mesenchymal stem cells: stem cell therapy perspectives for type 1 diabetes. Diabetes Metab 2009; 35: 85-93

[43] Corcione A, Benvenuto F, Ferretti E, et al. Human mesenchymal stem cells modulate B-cell functions. Blood 2006; 107: 367-372.

[44] Spaggiari GM, Capobianco A, Abdelrazik H, Becchetti F, Mingari MC, Moretta L. Mesenchymal stem cells inhibit natural killer-cell proliferation, cytotoxicity, and cytokine production: role of indoleamine 2,3-dioxygenase and prostaglandin E2. Blood 2008; 111: $1327-33$

[45] Li DS, Warnock GL, Tu HJ, et al. Do immunotherapy and $\beta$ cell replacement play a sinergistic role in the treatment of type 1 diabetes? Life Sciences 2009; 85: 549-56.

[46] Nichols J, Cooke A. Overcoming self-destruction in pancreas. Curr Opin Biotechnol 2009; 20: 511-15.

[47] Weiss ML, Anderson C, Medicetty S, et al. Immune properties of human umbilical cord Wharton's jelly-derived cells. Stem Cells 2008; 26: 2865-74.

[48] Alma J, Nauta W, Fibbe E. Immunomodulatory properties of mesenchymal stromal cells. Blood 2007; 110: 3499-506.
[49] Selmani Z, Naji A, Gaiffe E, et al. HLA-G is a crucial immunosuppressive molecule secreted by adult human mesenchymal stem cells. Transplantation 2009; 87(9 Suppl.): S62-S66.

[50] Anzalone R, Lo Iacono M, Loria T, et al. Wharton's jelly mesenchymal stem cells as candidates for beta cells regeneration: Extending the differentiative and immunomodulatory benefits of adult mesenchymal stem cells for the treatment of type 1 diabetes. Stem Cell Rev Rep 2011; 7: 342-63.

[51] Lee N, Llano M, Carretero M, et al. HLA-E is a major ligand for the natural killer inhibitory receptor CD94yNKG2A. Proc Natl Acad Sci USA 1998; 95: 5199-204.

[52] La Rocca G, Anzalone R, Farina F. The expression of CD68 in human umbilical cord mesenchymal stem cells: new evidences of presence in non-myeloid cell types. Scand J Immunol 2009; 70 (2): 161-2.

[53] Najar M, Raicevic G, Boufker HI, et al. Mesenchymal stromal cells use PGE2 to modulate activation and proliferation of lymphocyte subsets: combined comparison of adipose tissue, Wharton's Jelly and bone marrow sources. Cell Immunol 2010; 264: 171-9.

[54] Leitner J, Klause C, Pickl WF, et al. B7-H3 is a potent inhibitor of human T-cell activation: No evidence for B7-H3 and TREML2 interaction. Eur. J. Immunol. 2009; 39: 1754-64

[55] Sansom DM, Manzotti CN, Zheng Y. What's the difference between CD80 and CD86? Trends Immunol 2003; 24: 313-8.

[56] Anzalone R, Farina F, Zummo G, La Rocca G. Recent patents and advances on isolation and cellular therapy applications of mesenchymal stem cells from human umbilical cord Wharton's jelly. Recent Pat Regen Med 2011; 1: 216-27.

[57] La Rocca G, Anzalone R, Magno F, Farina F, Cappello F, Zummo G. Cigarette smoke exposure inhibits extracellular MMP-2 (gelatinose A) activity in human lung fibroblasts. Resp Res 2007; 8: 23.

[58] Petit B, Masuda K, D'Souza A, et al. Characterization of crosslinked collagens synthesized by mature articular chondrocytes cultured in alginate beads: comparison of two distinct matrix compartments. Experimental Cell Research 1996; 225: 151-61.

[59] Anzalone R, Corrao S, Lo Iacono M, et al. Isolation and Characterization of CD276+/HLA-E+ Human Subendocardial Mesenchymal Stem Cells from Chronic Heart Failure Patients: Analysis of Differentiative Potential and Immunomodulatory Markers Expression. Stem Cells Dev 2013; 22: 1-17.

[60] Walsh NE, Brooks P, Hazes JM, et al. Standards of care for acute and chronic musculoskeletal pain: The bone and joint decade (2000-2010). Arch Phys Med Rehabil 2008; 89: 1830-45

[61] Mao, JJ. De novo formation and regeneration of vascularized tissue from tissue progenitor cells and vascular progenitor cells. US20100136114 (2010).

[62] Ronziere MC, Perrier E, Mallein-Gerin F, Freyria AM. Chondrogenic potential of bone marrow- and adipose tissuederived adult human mesenchymal stem cells. Biomed Mater Eng 2010; 20: 14558

[63] Baumgartner L, Arnhold S, Brixius K, Addicks K, Bloch W. Human mesenchymal stem cells: Influence of oxygen pressure on proliferation and chondrogenic differentiation in fibrin glue in vitro. J Biomed Mater Res A 2010; 93: 930-40.

[64] Lafont JE. Lack of oxygen in articular cartilage: consequences for chondrocyte biology. Int J Exp Pathol 2010; 91: 99-106

[65] Duda GN, Petersen A. New components and new bioreactor system for the culture and mechanical stimulation of biological material. EP2184347 (2009).

[66] Anzalone R, Lo Iacono M, Corrao S, et al. New emerging potentials for human Wharton's jelly mesenchymal stem cells: immunological features and hepatocyte-like differentiative capacity. Stem Cell Dev 2010; 19: 423-38

[67] Aggarwal S, Pittenger MF. Human mesenchymal stem cells modulate allogeneic immune cell responses. Blood 2005; 105: 1815-22.

[68] La Rocca G, Corrao S, Lo Iacono M, Corsello T, Farina F, Anzalone R. Novel Immunomodulatory markers espressed by human WJ-MSC: an update review in regenerative and reparative medicine. Open Tissue Eng Regen Med J 2012; 5: 50-8.

[69] Corrao S, Campanella C, Anzalone R, et al. Human Hsp10 and Early Pregnancy Factor (EPF) and their relationship and involvement in cancer and immunity: current knowledge and perspectives. Life Sci 2010; 86: 145-52. 
[70] Liu H, Kemeny DM, Heng BC, Ouyang HW, Melendez AJ, Cao T. The immunogenicity and immunomodulatory function of osteogenic cells differentiated from mesenchymal stem cells. J Immunol 2006; 176: 2864-71.

[71] Zheng ZH, Li XY, Ding J, Jia JF, Zhu P. Allogeneic mesenchymal stem cell and mesenchymal stem cell-differentiated chondrocyte suppress the responses of type II collagen-reactive $\mathrm{T}$ cells in rheumatoid arthritis. Rheumatology 2008; 47: 22-30.

[72] Chen X, McClurg A, Zhou GQ, McCaigue M, Armstrong MA, Li G. Chondrogenic differentiation alters the immunosuppressive property of bone marrow-derived mesenchymal stem cells, and the effect is partially due to the upregulated expression of B7 molecules. Stem Cells 2007; 25: 364-70. 